\title{
Effect of light quality on leaf photosynthetic characteristics and fruit quality of peach (Prunus persica L. Batch)
}

\author{
B.-B. ZHANG ${ }^{*}$ J.-L. XU*, M. ZHOU*, D.-H. YAN*, and R.-J. MA*,+ \\ Institute of Pomology, Jiangsu Academy of Agricultural Sciences/Jiangsu Key Laboratory of Horticultural Crop Genetic \\ Improvement, Nanjing, Jiangsu 210014, China* \\ Fenghuang Agricultural Science and Technology Company, Suzhou, Jiangsu 215612, China**
}

\begin{abstract}
Different light filters affect leaf photosynthetic features and fruit quality. Consequently, selecting the appropriate covering filter for rain-shelter cultivation of peaches is a key part of successful production. We used a late-maturing peach variety 'Xiahui 8' to study differences in leaf photosynthetic features, chlorophyll fluorescence characteristics, and fruit quality under neutral, red, yellow, green, and blue filter, with natural light as control. The results showed that the leaf photosynthetic ability and internal quality under the neutral filter treatment were elevated compared with the control, and the appearance color was the same as the control. Leaves under neutral filter could maintain higher photosynthetic ability than other filter treatments. In addition, the fruits could also keep higher quality when treated with neutral filter. Therefore, the application of neutral filter in rain-shelter cultivation of 'Xinhui 8' peaches is recommended for maintaining high photosynthetic capacity and for improving fruit quality.
\end{abstract}

Additional key words: appearance; internal quality; irradiance spectrum.

\section{Introduction}

Light is the main factor affecting the photosynthesis, growth, and development of plants (Kircher et al. 1999). Furthermore, the growth and development of plants and fruit formation are all based on photosynthesis, photomorphogenesis, and photoperiod adjustments. Under appropriate light conditions, $\mathrm{CO}_{2}$ fixation and net photosynthetic rates increase with elevated absorption of light energy by chlorophyll (Chl); however, excessive light inhibits photosynthesis and even leads to the photooxidation of photosynthetic apparatus (Cleland et al. 1986). The photosynthetic organs of fruit trees obtain energy from solar radiation, which the plant uses for its own growth and development. Moreover, the products of photosynthetic assimilation are continuously transported to the fruits and promote their growth and development, which is crucial for fruit tree varieties used in a commercial fruit production.

A previous study showed that the maturation period of 'Jonagold' apples advanced at varying levels of shading (8-12\%, 15-17\%, and 18-25\%), but no significant differences were observed in fruit firmness, soluble solid content (SSC), and titratable acid content (Widmer 2001). However, for 'Mondial Gala' apples, the fruit surface temperature was reduced with $25 \%$ shading, which effectively prevented sunburn but decreased SSC (Iglesias and Alegre 2006). In a previous publication, we demonstrated that shading alleviated photoinhibition in red-leaf peach leaves, which acted to prevent photo-oxidative

Received 8 February 2017, accepted 26 July 2017, published as online-first 13 April 2018.

${ }^{+}$Corresponding author; phone: +86-025-84390220, fax: +86-025-84391695, e-mail: marj311@163.com

Abbreviations: $a^{*}$ - red saturation; Ant - anthocyanin; $b^{*}-$ yellow saturation; $C$ - color chroma; Chl - chlorophyll; $C_{\mathrm{i}}-\mathrm{intercellular}$ $\mathrm{CO}_{2}$ concentration; CUE - carbon-use efficiency; DAFB - days after full bloom; $E$ - transpiration; ETR - electron transport rate; $\mathrm{F}_{0}$ - minimal fluorescence level in dark-adapted leaves; $\mathrm{F}_{0}{ }^{\prime}-$ minimal fluorescence level in light-adapted leaves; $\mathrm{F}_{\mathrm{m}}-\mathrm{maximal}$ fluorescence level in dark-adapted leaves; FM - fresh matter; $\mathrm{F}_{\mathrm{m}}{ }^{\prime}$ - maximal fluorescence level in light-adapted leaves; $\mathrm{F}_{\mathrm{s}}$ - steady-state fluorescence in the light-adapted state; $F_{\mathrm{v}}$ - variable fluorescence level in dark-adapted leaves; $\mathrm{F}_{\mathrm{v}} / \mathrm{F}_{\mathrm{m}}-\mathrm{maximum}$ quantum yield of PSII; $g_{\mathrm{s}}$ - stomatal conductance; $h^{\circ}$ - hue angle; HPLC - high performance liquid chromatography; $L^{*}-$ lightness; LUE - apparent light-use efficiency; $\mathrm{L}_{\mathrm{s}}$ - light-saturation point; NPQ - nonphotochemical quenching; $P_{\mathrm{N}}$ - net photosynthetic rate; qP - photochemical quenching coefficient; R/FR - red to far-red ratio; SSC - soluble solid content; WUE - water-use efficiency; $\Phi_{P S I I}$ - effective quantum yield of PSII photochemistry.

Acknowledgements: This study was supported by China Agriculture Research System (No. CARS-30) and Jiangsu Agriculture Science and Technology Innovation Fund (CX(15)1020). 
damage (Zhang et al. 2010). Another study showed that fruit bags of different colors allow radiation of different light qualities on the fruit, and the different bags had different effects on the appearance quality and inner quality of peaches (Ma et al. 2014, Zhang et al. 2015).

Light quality refers to the composition of the solar radiation spectrum and the energy contained in each band. During the growth and development of plants, light quality not only provides energy for photosynthesis, synthesis of organic matter, and growth (Rapparini et al. 1999, Bastías and Corelli-Grappadelli 2012, Shibuya et al. 2012), but also serves as an environmental signal to regulate the formation of fruit quality (Adams-Phillips et al. 2004, Koyama et al. 2012). Phytochrome, cryptochrome, protochlorophyllide, and $\mathrm{Chl}$ all play roles in the regulation of chloroplast development. Phytochrome mainly perceives red light and far-red light, as well as blue light and UV light. Cryptochrome primarily detects blue light and UV-A (Batschauer 1998). Plants are selective in that they cannot absorb full-wave band light. Studies have indicated that the development of plant photosynthetic organs is mediated by light quality, and that light with different wavelengths has various impacts on plant growth and development. For example, blue light changed the thickness of the leaf tissue and the phytochrome status in the tissue of peaches (Rapparini et al. 1999). Blue light also increased leaf numbers, Chl content, and stomata numbers in grapes (Poudel et al. 2008). Red light increased starch accumulation in birch leaves by inhibiting the transportation of photosynthetic products from the leaves (Sæbø et al. 1995), and increased the stem internode of grape seedlings (Poudel et al. 2008). Light signals with wavelengths over $600 \mathrm{~nm}$ had the most significant impact on the skin color chroma $(C)$, red saturation $\left(a^{*}\right)$, and yellow saturation $\left(b^{*}\right)$ (Dussi et al. 1995).

While most of the studies described above focused on the effect of monochromatic light on plant growth and development, the synergistic effect of compound light has also been investigated. Schuerger et al. (1997) explored the growth of sweet pepper under a mixed light treatment

\section{Materials and methods}

Plant material and experimental treatments: The experiment was conducted in the experimental peach orchard of the Fenghuang Agricultural Science and Technology Company in Suzhou city $\left(31.75^{\circ} \mathrm{N}, 120.64^{\circ} \mathrm{E}\right)$, Jiangsu Province, China. During the experiment, the average temperature was about $28.2^{\circ} \mathrm{C}$, and humidity was around $81.9 \%$. A late-ripening peach cultivar 'Xiahui 8 ', which matures in early August, was used for the experiment. The trees were five-years-old, grown on Maotao (Prunus persica L. Batch) rootstocks with a central leader tree form. Different types of filter with different colors were positioned above the trees before the fruit color changing period (100 d after full bloom [DAFB]). The size of the filter covering each tree was $2 \times 2 \times 3 \mathrm{~m}$ (length $\times$ width $\times$ of red/far-red and red/blue/far-red, and found that blue light is the dominant light quality affecting the anatomical structure of stems and the changes in leaf tissue. Xiong et al. (2011) demonstrated that the variation of light quality substantially influenced the morphology of stems and petioles, dry matter accumulation, and carbohydrate content in cucumbers, but had no dramatic impact on leaves and roots.

Light quality also has significant effects on fruit quality. Tomato fruit grown under light contained 30\% more sucrose and one-fold more starch and hexose than fruit grown in the dark (Guan et al. 1991). Fruit bags with different colors allow radiation of different light qualities on the fruit, and studies have shown that both the SSC and edible quality decreased in bagged fruit (Ni et al. 2011, Hudina and Stampar 2011).

Our study was performed in the middle and lower reaches of the Yangtze River, which is located in the subtropical or tropical monsoon climate zone of China. Consequently, the peach-growing season typically occurs when the groundwater level is generally high due to frequent and strong rainfall. We selected several floodresistant stocks for peach cultivation (Ma et al. 2013), but the expansion of these stocks is difficult to complete in a short period of time because of the slow turnover rate of trees in the peach orchards. Recently, researchers have been studying the potential of rain-shelter cultivation in peach production. Although the trees are grown in a relatively ventilated environment in rain-shelter cultivation, the long-term, low-light environment clearly affects growth, fruit quality, and yield of trees because peach is a species fond of light. Therefore, proper selection of rain-shelter filters is crucial in commercial rain-shelter production.

The purpose of this study was to investigate the effect of light quality on leaf photosynthetic characteristics, leaf $\mathrm{Chl}$ fluorescence parameters, and fruit quality in peaches, and to find the type of light quality that is effective in improving or maintaining leaf growth and fruit quality in peaches.

height). The frame for sustaining the filter was made of lead wire. Trees with no filter were selected for the control group. Six trees were used as replicates. All trees were planted in a south-north direction in single rows and were well managed according to conventional procedures.

Five types of filter (Shanghai Weikang Colored Filter Co., China) were employed for this study: neutral, red, yellow, green, and blue filter. The light transmittance of each type of filter was $57.2,56.7,56,55$, and $56.5 \%$, respectively. The radiant energy of the spectrum was measured by a $L I-1800$ portable spectroradiometer ( $L I-C O R$, USA). The components of representative irradiance spectrum in different filters were presented in the following table: 
The components of representative irradiance spectrum in different filters.

\begin{tabular}{lllllll}
\hline Filter type & Control & Neutral filter & Red filter & Yellow filter & Green filter & Blue filter \\
\hline Ultraviolet light $(300-400 \mathrm{~nm})\left[\mathrm{W} \mathrm{m}^{-2}\right]$ & 7.12 & 4.26 & 2.40 & 4.28 & 5.01 & 5.30 \\
Blue light $(400-510 \mathrm{~nm})\left[\mathrm{W} \mathrm{m}^{-2}\right]$ & 29.18 & 11.89 & 2.86 & 13.03 & 16.56 & 28.35 \\
Green light $(510-610 \mathrm{~nm})\left[\mathrm{W} \mathrm{m}^{-2}\right]$ & 48.97 & 29.59 & 1.85 & 31.42 & 32.10 & 5.19 \\
Red light $(610-720 \mathrm{~nm})\left[\mathrm{W} \mathrm{m}^{-2}\right]$ & 56.77 & 33.50 & 42.07 & 32.46 & 14.38 & 19.58 \\
Near-infrared light $\left(720-1,100 \mathrm{~nm}^{-}\left[\mathrm{W} \mathrm{m}^{-2}\right]\right.$ & 134.78 & 75.58 & 104.81 & 71.56 & 82.38 & 95.03 \\
Solar radiation (300-1,100 nm) $\left[\mathrm{W} \mathrm{m}^{-2}\right]$ & 276.82 & 154.82 & 154.00 & 152.75 & 150.44 & 153.45 \\
Red/Far-red (R/FR) & 1.08 & 1.21 & 1.02 & 1.18 & 0.47 & 0.23 \\
Red/Blue (R/B) & 1.95 & 2.82 & 14.71 & 2.49 & 0.87 & 0.69 \\
\hline
\end{tabular}

Photosynthesis and Chl fluorescence parameters were measured from 10:00 to 11:00 h (Beijing time) using mature and fully expanded leaves from different treatments at harvest. Leaves at the same position were used for leaf $\mathrm{Chl}$ content measurements.

Twenty fruits were collected from each tree for each replication at harvest time (132 DAFB). Harvested fruits were instantly put in ice boxes and carried back to the laboratory for assay. After fruit mass, fruit color, firmness, and soluble solid content measurements, skin and flesh samples were separated and immediately frozen in liquid nitrogen, then stored at $-70^{\circ} \mathrm{C}$ until they were used for other aspects of the study.

Fruit mass, firmness, and SSC: Fruit mass was determined using a digital electrical balance. Texture was measured using a puncture test with an 8-mm-diameter needle in a TA-XT plus texture analyzer (Stable Micro Systems, UK). The studies were conducted at a pre-test speed of $1 \mathrm{~mm} \mathrm{~s}^{-1}$, test speed of $2 \mathrm{~mm} \mathrm{~s}^{-1}$, and a distance of $5 \mathrm{~mm}$. The SSC of the materials was measured using normal commercial procedures. The fruit was juice squeezed from two opposite equatorial locations and read with a digital hand-held pocket refractometer $P A L-1$ (Atago, Tokyo, Japan) in ${ }^{\circ}$ Brix at $20^{\circ} \mathrm{C}$ (Mitchell et al. 1974, Infante et al. 2011).

Fruit color and skin pigment: Fruit surface color was measured with a ColorQuest XE spectrophotometer (Hunter Lab, Reston, USA) in the CIE Lab space using $L^{*}$ (lightness), $a^{*}$, and $b^{*}$ modes. Six different positions were evaluated for each fruit for each treatment. Values for $a^{*}$ and $b^{*}$, respectively, were averaged and the $a^{*} / b^{*}$ ratio was calculated (Brecht et al. 1986). The hue angle $\left(h^{\circ}\right)$ and $C$ parameters were also calculated as: $h^{\circ}=\tan ^{-1}\left(b^{*} / a^{*}\right)$ and $C=\left(a^{* 2}+b^{* 2}\right)^{1 / 2}$ (Voss 1992, Koukounaras et al. 2009).

Anthocyanin (Ant) content was determined from skin $(2 \mathrm{~g})$ extracted with $10 \mathrm{ml}$ of $1 \% \mathrm{HCl}-$ methanol for $24 \mathrm{~h}$. The extract was filtered and its absorbance determined at 650, 620, and $530 \mathrm{~nm}$, respectively. The Ant absorbance measurement was based on the formula: $(A)=\left(A_{530}-A_{620}\right)$ $-0.1 \times\left(\mathrm{A}_{650}-\mathrm{A}_{620}\right)$ using a spectrophotometer (UV-6300PC, Mapada, China) and its content was determined using a molar extinction coefficient of $4.62 \times 10^{4}$ (Zapsalis and Francis 1965).

The Chl content was determined from skin $(2 \mathrm{~g})$ extracted with $10 \mathrm{ml}$ of $95 \%$ ethanol at $25^{\circ} \mathrm{C}$ overnight. $\mathrm{Chl}$ in the supernatant was quantified with a spectrophotometer $(U V-6300 P C$, Mapada, China) at $665 \mathrm{~nm}$ and $649 \mathrm{~nm}$.

$$
\begin{aligned}
& \text { Chl } a=13.95 \mathrm{~A}_{665}-6.88 \mathrm{~A}_{649} \\
& \text { Chl } b=24.96 \mathrm{~A}_{649}-7.32 \mathrm{~A}_{665} \\
& \text { Chl }=\text { Chl } a+\text { Chl } b
\end{aligned}
$$

Assays were carried out three times on duplicate samples. The blank control was 95\% (v/v) ethanol (Lichtenthaler and Wellburn 1983). The contents for both $\mathrm{Chl} a$ and $\mathrm{Chl} b$ were expressed as mg per $\mathrm{g}$ of fresh matter (FM).

Skin antioxidant components: Two grams of frozen skin was homogenized with $10 \mathrm{ml}$ of ice-cold $1 \% \mathrm{HCl}-$ methanol solution and then extracted at $4{ }^{\circ} \mathrm{C}$ for $48 \mathrm{~h}$, and then filtered. Absorbance was measured at $325 \mathrm{~nm}$ and $280 \mathrm{~nm}$ using a spectrophotometer (UV-6300PC, Mapada, China) and a $1 \% \mathrm{HCl}-$ methanol solution as reference. Rutin solution was used to form a standard curve of total flavonoid. The content of phenolic compounds was calculated with the standard curve obtained on the basis of content of gallic acid expressed as $\mathrm{mg} \mathrm{g}^{-1}$ (FM) (Fukumoto and Mazza 2000, Pourmorad et al. 2006, Tawaha et al. 2007).

Fruit soluble sugar: Flesh sucrose, glucose, fructose, and sorbitol standards were purchased from Sigma-Aldrich (St. Louise, USA). Sugars were separated and quantified by high performance liquid chromatography (HPLC) analysis (Agilent 1100). The HPLC system was equipped with a quaternary pump, an autosampler, a refractive index detector (RID) with carbohydrate column (CARBOSep CHO-620 CA, $10 \mu \mathrm{m}$ and $6 \mathrm{~mm} \times 250 \mathrm{~mm}$, Transgenomic Inc., USA) at $80^{\circ} \mathrm{C}$ with a flow rate of $0.5 \mathrm{ml} \mathrm{min} \mathrm{mi}^{-1}$. HPLC conditions were as follows: mobile phase, double distilled water; injection volume, $5 \mu \mathrm{l}$. Total sugar content $=$ sucrose content + glucose content + fructose content + sorbitol content. 
Fruit organic acid: Organic acid content was also analyzed by the HPLC system using a diode array detector with an Agilent ZORBAX Eclipse XDB-C18 column (4.6 $\mathrm{mm} \times 250 \mathrm{~mm}$ ID, $5 \mu \mathrm{m})$ (Agilent Technology, USA). The mobile phase was carried out with $0.02 \mathrm{~mol} \mathrm{l}^{-1}$ $\mathrm{KH}_{2} \mathrm{PO}_{4}$ (pH 2.7). Chromatography separation was performed at $25^{\circ} \mathrm{C}$ with a flow rate of $0.5 \mathrm{ml} \mathrm{min}$. The detected organic acids were malic acid, citric acid, and quinic acid; absorbance was measured at $214 \mathrm{~nm}$ (total acid content $=$ malic acid content + citric acid content + quinic acid content). The ratio between soluble sugar and organic acid was also calculated as the sugar acid ratio.

Net photosynthetic rate $\left(P_{\mathrm{N}}\right)$, stomatal conductance $\left(g_{s}\right)$, transpiration $(E)$, and water-use efficiency (WUE) were measured with an open system $C I R A S-1$ portable infrared gas analyzer photosynthesis system (PP System, USA). WUE was calculated (WUE $=P_{\mathrm{N}} / E$ ) as described by Nijs et al. (1997). Meanwhile, the following indicators were calculated: apparent light-use efficiency (LUE) $=$ $P_{\mathrm{N}} / \mathrm{PAR}$, carbon-use efficiency $(\mathrm{CUE})=P_{\mathrm{N}} / C_{\mathrm{i}}\left(C_{\mathrm{i}}\right.$, intercellular $\mathrm{CO}_{2}$ concentration), light-saturation point $\left(\mathrm{L}_{\mathrm{s}}\right)=$ $1-C_{\mathrm{i}} / C_{\mathrm{a}}$ (Marshall and Biscoe 1980).

Leaf $\mathrm{Chl}$ content and $\mathrm{Chl}$ fluorescence: The method was the same as the skin Chl content measurement and the mass of the leaf used in this experiment was $0.2 \mathrm{~g}$. Chl fluorescence emissions of leaves of intact peach trees were measured by a fluorometer (FMS-2, Hansatech Instruments Ltd., UK). Prior to each measurement, a clip was placed on the leaf for $30 \mathrm{~min}$ for dark adaptation. Minimum fluorescence level in dark-adapted leaves $\left(\mathrm{F}_{0}\right)$ was determined by applying a weak modulated irradiance
[6 $\mu \mathrm{mol}\left(\right.$ photon) $\mathrm{m}^{-2} \mathrm{~s}^{-1}$ ] and the maximal fluorescence level in dark-adapted leaves $\left(\mathrm{F}_{\mathrm{m}}\right)$, was induced by applying a short pulse $(0.8 \mathrm{~s})$ of saturating radiation $[9,000$ $\mu \mathrm{mol}$ (photon) $\left.\mathrm{m}^{-2} \mathrm{~s}^{-1}\right]$. Then, the leaves were continuously illuminated with a white actinic light, which was equivalent to the actual growth light, in order to measure steady-state fluorescence in the light-adapted state $\left(F_{s}\right)$ and maximal fluorescence level in the light-adapted leaves $\left(\mathrm{F}_{\mathrm{m}}{ }^{\prime}\right)$. The minimal fluorescence level in light-adapted leaves $\left(\mathrm{F}_{0}{ }^{\prime}\right)$ was determined by turning off the actinic light and immediately applying a 2-s far-red pulse. The maximum quantum efficiency of PSII photochemistry was calculated as $F_{v} / F_{m}=\left(F_{m}-F_{0}\right) / F_{m}\left(F_{v}\right.$, variable fluorescence level in dark-adapted leaves). The effective quantum yield of PSII photochemistry was calculated as $\Phi_{\mathrm{PSII}}=$ $\left(\mathrm{F}_{\mathrm{m}}{ }^{\prime}-\mathrm{F}_{\mathrm{s}}\right) / \mathrm{F}_{\mathrm{m}}{ }^{\prime}$ (Genty et al. 1989). The electron transport rate was also calculated according to Genty et al. (1989) as: $\mathrm{ETR}=\mathrm{ETR}$ factor $\times \Phi_{\mathrm{PSII}} \times \mathrm{PAR} \times 0.5$, where ETR factor is 0.84 . This factor corresponds to the fraction of incident radiation absorbed by various leaf species. The nonphotochemical quenching was calculated as: NPQ = $\left(F_{m}-F_{m}{ }^{\prime}\right) / F_{m}{ }^{\prime}$ (Maxwell and Johnson 2000). Photochemical quenching coefficient $\left(\mathrm{q}_{\mathrm{p}}\right)$ was calculated according to van Kooten and Snel (1990).

Statistical analysis: One-way analysis of variance (ANOVA) was carried out using an SPSS computer package for all datasets. The values were the means of all measurements. Comparisons of means were determined through Duncan's new multiple range tests. All experimental results were presented as the mean of three replicates. A difference was considered significant at $P<0.05$.

\section{Results}

Photosynthetic characteristics of peach leaves: As seen in Table 1, Chl contents under filter treatments with various light qualities were significantly higher than the Chl content of the control. When comparing the different filters, the highest Chl contents were observed in plants under the red and yellow filters, followed by the neutral and blue filters, and the lowest one was under the green filter treatment.

Table 1. Effect of light quality on leaf photosynthetic indexes in peach. Data represent means $\pm \mathrm{SD}$ of three replicates. For each variable, means with different lowercase letters are significantly different at $P<0.05$. Chl - chlorophyll; $C_{\mathrm{i}}-$ intercellular $\mathrm{CO}_{2}$ concentration; CUE - carbon-use efficiency; $E$ - transpiration; $g_{s}$ - stomatal conductance; LUE - apparent light-use efficiency; $L_{s}-$ light-saturation point; $P_{\mathrm{N}}-$ net photosynthetic rate; WUE - water-use efficiency.

\begin{tabular}{lllllll}
\hline Treatment & Control & Neutral filter & Red filter & Yellow filter & Green filter & Blue filter \\
\hline $\mathrm{Chl}\left[\mathrm{mg} \mathrm{g}^{-1}(\mathrm{FM})\right]$ & $4.66 \pm 0.21^{\mathrm{c}}$ & $4.97 \pm 0.15^{\mathrm{b}}$ & $5.25 \pm 0.09^{\mathrm{a}}$ & $5.35 \pm 0.14^{\mathrm{a}}$ & $3.58 \pm 0.08^{\mathrm{d}}$ & $4.95 \pm 0.12^{\mathrm{b}}$ \\
$P_{\mathrm{N}}\left[\mu \mathrm{mol}\left(\mathrm{CO}_{2}\right) \mathrm{m}^{-2} \mathrm{~s}^{-1}\right]$ & $12.10 \pm 0.39^{\mathrm{b}}$ & $16.22 \pm 1.01^{\mathrm{a}}$ & $13.08 \pm 1.50^{\mathrm{b}}$ & $10.90 \pm 0.98^{\mathrm{c}}$ & $1.18 \pm 0.30^{\mathrm{d}}$ & $2.15 \pm 0.49^{\mathrm{d}}$ \\
$E\left[\mathrm{mmol}\left(\mathrm{H}_{2} \mathrm{O}\right) \mathrm{m}^{-2} \mathrm{~s}^{-1}\right]$ & $3.74 \pm 0.24^{\mathrm{a}}$ & $4.05 \pm 0.62^{\mathrm{a}}$ & $3.82 \pm 0.62^{\mathrm{a}}$ & $3.14 \pm 0.41^{\mathrm{b}}$ & $1.24 \pm 0.20^{\mathrm{c}}$ & $1.32 \pm 0.16^{\mathrm{c}}$ \\
$\mathrm{WUE}\left[\mathrm{mmol}^{\mathrm{a}}\left(\mathrm{CO}_{2}\right) \mathrm{mol}\left(\mathrm{H}_{2} \mathrm{O}\right)^{-1}\right] 3.24 \pm 0.13^{\mathrm{b}}$ & $4.07 \pm 0.55^{\mathrm{a}}$ & $3.78 \pm 0.65^{\mathrm{a}}$ & $3.86 \pm 0.31^{\mathrm{a}}$ & $0.89 \pm 0.09^{\mathrm{d}}$ & $1.74 \pm 0.23^{\mathrm{c}}$ \\
$\mathrm{LUE}$ & $12.13 \pm 0.42^{\mathrm{b}}$ & $16.32 \pm 1.01^{\mathrm{a}}$ & $13.06 \pm 1.45^{\mathrm{b}}$ & $10.97 \pm 1.05^{\mathrm{c}}$ & $1.23 \pm 0.37^{\mathrm{d}}$ & $2.15 \pm 0.49^{\mathrm{d}}$ \\
$\mathrm{CUE}\left[\mathrm{mol} \mathrm{m}^{-2} \mathrm{~s}^{-1}\right]$ & $0.063 \pm 0.001^{\mathrm{b}}$ & $0.079 \pm 0.011^{\mathrm{a}}$ & $0.055 \pm 0.007^{\mathrm{c}}$ & $0.048 \pm 0.006^{\mathrm{c}}$ & $0.004 \pm 0.001^{\mathrm{d}}$ & $0.008 \pm 0.002^{\mathrm{d}}$ \\
$C_{\mathrm{i}}\left[\mu \mathrm{mol}\left(\mathrm{CO}_{2}\right) \mathrm{mol}^{-1}\right]$ & $177.00 \pm 10.18^{\mathrm{d}}$ & $214.83 \pm 2.31^{\mathrm{c}}$ & $237.50 \pm 14.03^{\mathrm{c}}$ & $230.33 \pm 2.06^{\mathrm{c}}$ & $337.83 \pm 7.49^{\mathrm{a}}$ & $290.67 \pm 8.12^{\mathrm{b}}$ \\
$g_{\mathrm{s}}\left[\mu \mathrm{mol}\left(\mathrm{H}_{2} \mathrm{O}\right) \mathrm{m}^{-2} \mathrm{~s}^{-1}\right]$ & $108.00 \pm 9.42^{\mathrm{b}}$ & $158.00 \pm 9.30^{\mathrm{a}}$ & $158.50 \pm 9.80^{\mathrm{a}}$ & $102.00 \pm 8.13^{\mathrm{b}}$ & $32.17 \pm 8.04^{\mathrm{c}}$ & $38.00 \pm 6.16^{\mathrm{c}}$ \\
$\mathrm{L}_{\mathrm{s}}$ & $0.541 \pm 0.022^{\mathrm{a}}$ & $0.507 \pm 0.024^{\mathrm{a}}$ & $0.434 \pm 0.033^{\mathrm{b}}$ & $0.443 \pm 0.014^{\mathrm{b}}$ & $0.199 \pm 0.078^{\mathrm{d}}$ & $0.300 \pm 0.081^{\mathrm{c}}$ \\
\hline
\end{tabular}


Among different treatments, the $P_{\mathrm{N}}, E$, WUE, LUE, and CUE values were the highest under the neutral filter, and the lowest one of these five indicators was seen under the green and blue filter treatments, but the WUE of blue filter was significantly higher than that of the green filter. Compared with the control, the $P_{\mathrm{N}}$, WUE, LUE, and CUE under neutral filter were significantly higher, but no substantial difference was observed in $E$. The $P_{\mathrm{N}}, E$, and LUE in the red filter treatment did not exhibit differences in comparison with those of the control, but these values under the red filter and control were dramatically higher than those in the yellow filter treatment. Both WUE and CUE were similar in the red and yellow filter treatments, with their WUE significantly higher and CUE lower than that of control.

All the filter treatments significantly increased the $C_{\mathrm{i}}$ of leaves, especially, by the green filter. The $g_{\mathrm{s}}$ measured in the yellow filter treatment was similar to that in the control, however, those in the neutral and red filter treatments were higher than control, and that of the green and blue filters was opposite. Regarding $\mathrm{L}_{\mathrm{s}}$, neutral filter was similar to the control, and other filters were all significantly lower than the control, with the lowest value found for the blue filter treatment.

Therefore, the neutral filter treatment could ensure the $E$ of peach leaves, and improve the photosynthetic capacity of leaves and the utilization efficiency of water, light, and $\mathrm{CO}_{2}$. Those capacities were substantially reduced in the green and blue filter treatments, and were not conducive to maintenance of leaf photosynthetic performance.

Chl fluorescence parameters: No significant difference was observed in $\mathrm{F}_{\mathrm{m}}$ between neutral filter and the control, but all other filters were substantially higher than the control (Table 2). The highest $F_{0}$ and $F_{m}$ were seen in the blue filter treatment, and $F_{m}$ in yellow filter was similar to that of blue filter. For the $F_{v} / F_{m}$, it showed no significant difference between green/blue filters and the control, while the neutral, red, and yellow filters were comparable, with the value substantially higher than that of the control.

Comparing the $\mathrm{F}_{\mathrm{s}}, \mathrm{F}_{\mathrm{m}}$, $\Phi_{\mathrm{PSII}}$, and $\mathrm{q}_{\mathrm{P}}$ of different treatments, the blue filter treatment exhibited the highest level, followed by the green filter. In addition, these indicators in the red and yellow treatments were significantly higher than those of control, while the $F_{\mathrm{s}}$ and $\mathrm{F}_{\mathrm{m}}$ ' of the neutral treatment were comparable to those of the control group. The $\mathrm{q}_{\mathrm{N}}$ and NPQ under various treatments showed the same pattern, and the order from the greatest to the smallest was: control, neutral, red filter $>$ yellow filter $>$ green filter $>$ blue filter. The ETR of all filter treatments was significantly higher than that of the control, with the highest in blue filter, then the red filter. ETR was relatively low in the neutral, yellow, and green treatments, and the values of the latter three were similar.

Skin color: Other than neutral filter, $L^{*}$ of all other light quality filters was significantly elevated with the highest level in the red and yellow filters (Table 3). Red, yellow, and green filters introduced a substantially higher $b^{*}$ than the control, while no difference was seen in the neutral and blue filter treatments. The pattern of $a^{*}$ and $a^{*} / b^{*}$ in all treatments was the same with the order of control, neutral, blue filter $>$ green filter $>$ red filter $>$ yellow filter, but the order of the $h^{\circ}$ was the opposite of $a^{*}$ and $a^{*} / b^{*}$. In addition, the green filter treatment significantly improved the $C$ of the fruits compared with the control, while yellow filter reduced it, and all others showed no substantial changes. The neutral and blue filter, along with the control, produced a desired red appearance in the color of the fruit (Fig. 1), but other treatments exhibited a light red color, which was consistent with the $a^{*}$ and $a^{*} / b^{*}$.

Table 2. Effect of light quality on leaf chlorophyll fluorescence parameters in peach. Data represent means \pm SD of three replicates. For each variable, means with different lowercase letters are significantly different at $P<0.05 . \mathrm{F}_{0}$ - minimal fluorescence level in darkadapted leaves; $\mathrm{F}_{0}{ }^{\prime}$ - minimal fluorescence level in light-adapted leaves; $\mathrm{F}_{\mathrm{m}}$ - maximal fluorescence level in dark-adapted leaves; $\mathrm{F}_{\mathrm{m}}{ }^{\prime}-$ maximal fluorescence level in light-adapted leaves; $F_{s}$ - steady-state fluorescence in the light-adapted state; $F_{v}$ - variable fluorescence level in dark-adapted leaves; $\mathrm{F}_{\mathrm{v}} / \mathrm{F}_{\mathrm{m}}$ - maximal quantum yield of PSII; NPQ - nonphotochemical quenching; qP - photochemical quenching coefficient; $\Phi_{\text {PSII }}$ - effective quantum yield of PSII photochemistry.

\begin{tabular}{lllllll}
\hline Treatment & Control & Neutral filter & Red filter & Yellow filter & Green filter & Blue filter \\
\hline$F_{0}[\mathrm{mV}]$ & $93.67 \pm 2.50^{\mathrm{d}}$ & $87.17 \pm 6.82^{\mathrm{e}}$ & $111.83 \pm 6.88^{\mathrm{b}}$ & $99.83 \pm 1.33^{\mathrm{c}}$ & $102.33 \pm 3.01^{\mathrm{c}}$ & $139.33 \pm 5.57^{\mathrm{a}}$ \\
$\mathrm{F}_{\mathrm{m}}[\mathrm{mV}]$ & $702.50 \pm 24.64^{\mathrm{d}}$ & $689.83 \pm 21.75^{\mathrm{d}}$ & $950.17 \pm 32.15^{\mathrm{a}}$ & $875.67 \pm 18.56^{\mathrm{b}}$ & $800.00 \pm 13.47^{\mathrm{c}}$ & $980.83 \pm 29.43^{\mathrm{a}}$ \\
$\mathrm{F}_{\mathrm{v}} / \mathrm{F}_{\mathrm{m}}$ & $0.865 \pm 0.003^{\mathrm{b}}$ & $0.874 \pm 0.003^{\mathrm{a}}$ & $0.875 \pm 0.013^{\mathrm{a}}$ & $0.881 \pm 0.004^{\mathrm{a}}$ & $0.865 \pm 0.005^{\mathrm{b}}$ & $0.859 \pm 0.008^{\mathrm{b}}$ \\
$\mathrm{F}_{\mathrm{s}}$ & $182.00 \pm 8.53^{\mathrm{d}}$ & $169.83 \pm 7.08^{\mathrm{d}}$ & $197.50 \pm 5.24^{\mathrm{c}}$ & $218.50 \pm 1.87^{\mathrm{b}}$ & $218.67 \pm 2.69^{\mathrm{b}}$ & $274.00 \pm 6.72^{\mathrm{a}}$ \\
$\mathrm{F}_{\mathrm{m}}$ & $285.67 \pm 10.42^{\mathrm{e}}$ & $284.33 \pm 10.11^{\mathrm{e}}$ & $372.67 \pm 9.79^{\mathrm{d}}$ & $399.50 \pm 8.93^{\mathrm{c}}$ & $449.83 \pm 8.22^{\mathrm{b}}$ & $759.17 \pm 8.77^{\mathrm{a}}$ \\
$\Phi_{\text {PSII }}$ & $0.374 \pm 0.020^{\mathrm{e}}$ & $0.427 \pm 0.017^{\mathrm{d}}$ & $0.470 \pm 0.007^{\mathrm{c}}$ & $0.502 \pm 0.013^{\mathrm{b}}$ & $0.514 \pm 0.030^{\mathrm{b}}$ & $0.637 \pm 0.029^{\mathrm{a}}$ \\
$\mathrm{qP}_{\mathrm{P}}$ & $0.564 \pm 0.028^{\mathrm{d}}$ & $0.613 \pm 0.030^{\mathrm{c}}$ & $0.686 \pm 0.041^{\mathrm{b}}$ & $0.660 \pm 0.025^{\mathrm{b}}$ & $0.660 \pm 0.025^{\mathrm{b}}$ & $0.790 \pm 0.021^{\mathrm{a}}$ \\
$\mathrm{q}_{N}$ & $0.687 \pm 0.017^{\mathrm{a}}$ & $0.673 \pm 0.033^{\mathrm{a}}$ & $0.689 \pm 0.016^{\mathrm{a}}$ & $0.615 \pm 0.024^{\mathrm{b}}$ & $0.505 \pm 0.055^{\mathrm{c}}$ & $0.263 \pm 0.010^{\mathrm{d}}$ \\
$\mathrm{NPQ}$ & $1.462 \pm 0.091^{\mathrm{a}}$ & $1.437 \pm 0.180^{\mathrm{a}}$ & $1.553 \pm 0.094^{\mathrm{a}}$ & $1.196 \pm 0.104^{\mathrm{b}}$ & $0.790 \pm 0.160^{\mathrm{c}}$ & $0.292 \pm 0.015^{\mathrm{d}}$ \\
ETR $\left[\mu \mathrm{mol} \mathrm{m}^{-2} \mathrm{~s}^{-1}\right]$ & $212.12 \pm 8.14^{\mathrm{d}}$ & $297.45 \pm 13.54^{\mathrm{c}}$ & $342.72 \pm 9.02^{\mathrm{b}}$ & $315.00 \pm 8.18^{\mathrm{c}}$ & $316.61 \pm 8.70^{\mathrm{c}}$ & $430.03 \pm 5.64^{\mathrm{a}}$ \\
\hline
\end{tabular}


Table 3. Effect of light quality on skin color in peach. Data represent means $\pm \mathrm{SD}$ of three replicates. For each variable, means with different lowercase letters are significantly different at $P<0.05 . a^{*}-$ red saturation; $b^{*}$-yellow saturation; $C-$ color chroma; $h^{\circ}-$ hue angle; $L^{*}-$ lightness.

\begin{tabular}{lllllll}
\hline Treatment & $L^{*}$ & $a^{*}$ & $b^{*}$ & $a^{*} / b^{*}$ & $C$ & $h^{\circ}$ \\
\hline Control & $58.08 \pm 0.78^{\mathrm{c}}$ & $21.45 \pm 2.17^{\mathrm{a}}$ & $20.67 \pm 1.03^{\mathrm{b}}$ & $1.12 \pm 0.25^{\mathrm{a}}$ & $30.77 \pm 0.38^{\mathrm{b}}$ & $44.84 \pm 1.47^{\mathrm{d}}$ \\
Neutral filter & $58.82 \pm 0.55^{\mathrm{c}}$ & $19.83 \pm 0.58^{\mathrm{a}}$ & $22.32 \pm 0.79^{\mathrm{b}}$ & $0.96 \pm 0.18^{\mathrm{a}}$ & $30.99 \pm 0.22^{\mathrm{b}}$ & $49.39 \pm 2.59^{\mathrm{c}}$ \\
Red filter & $66.33 \pm 1.03^{\mathrm{a}}$ & $13.27 \pm 0.25^{\mathrm{c}}$ & $25.50 \pm 0.63^{\mathrm{a}}$ & $0.58 \pm 0.04^{\mathrm{c}}$ & $30.33 \pm 0.09^{\mathrm{b}}$ & $62.25 \pm 1.17^{\mathrm{b}}$ \\
Yellow filter & $68.95 \pm 1.23^{\mathrm{a}}$ & $9.68 \pm 1.33^{\mathrm{d}}$ & $26.00 \pm 0.28^{\mathrm{a}}$ & $0.41 \pm 0.11^{\mathrm{d}}$ & $28.72 \pm 0.28^{\mathrm{c}}$ & $69.30 \pm 2.14^{\mathrm{a}}$ \\
Green filter & $62.57 \pm 0.46^{\mathrm{b}}$ & $15.71 \pm 0.10^{\mathrm{b}}$ & $25.94 \pm 0.34^{\mathrm{a}}$ & $0.69 \pm 0.08^{\mathrm{b}}$ & $32.19 \pm 0.59^{\mathrm{a}}$ & $59.48 \pm 2.36^{\mathrm{b}}$ \\
Blue filter & $60.54 \pm 0.69^{\mathrm{b}}$ & $18.14 \pm 2.06^{\mathrm{a}}$ & $22.83 \pm 0.87^{\mathrm{b}}$ & $0.88 \pm 0.16^{\mathrm{a}}$ & $30.50 \pm 0.17^{\mathrm{b}}$ & $52.28 \pm 3.21^{\mathrm{c}}$ \\
\hline
\end{tabular}

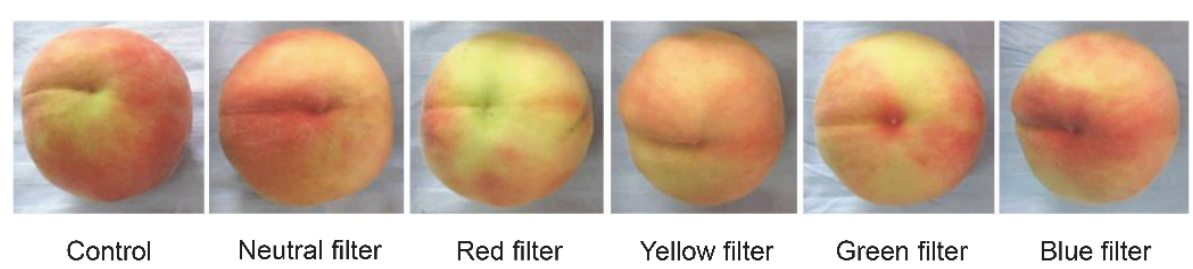

Fig. 1. Skin color differences between different light quality treatments in peach. Fruit pictures represent control, neutral filter, red filter, yellow filter, green filter, and blue filter from left to right, respectively.

Table 4. Effect of light quality on skin pigment contents in peach. Data represent means \pm SD of three replicates. For each variable, means with different lowercase letters are significantly different at $P<0.05$. Ant - anthocyanin; Chl - chlorophyll.

\begin{tabular}{lllll}
\hline Treatment & Ant $[\mathrm{nmol} \mathrm{g}$ & \\
\hline Control & $27.59 \pm 2.24^{\mathrm{a}}$ & $2.89 \pm 0.33^{\mathrm{d}}$ & $0.331 \pm 0.022^{\mathrm{d}}$ & $0.291 \pm 0.016^{\mathrm{c}}$ \\
Neutral filter & $30.51 \pm 3.34^{\mathrm{a}}$ & $4.96 \pm 0.39^{\mathrm{b}}$ & $0.408 \pm 0.016^{\mathrm{b}}$ & $0.339 \pm 0.019^{\mathrm{b}}$ \\
Red filter & $14.95 \pm 2.20^{\mathrm{c}}$ & $4.50 \pm 0.44^{\mathrm{b}}$ & $0.371 \pm 0.018^{\mathrm{c}}$ & $0.292 \pm 0.025^{\mathrm{c}}$ \\
Yellow filter & $11.97 \pm 2.07^{\mathrm{c}}$ & $3.68 \pm 0.37^{\mathrm{c}}$ & $0.359 \pm 0.011^{\mathrm{c}}$ & $0.278 \pm 0.014^{\mathrm{c}}$ \\
Green filter & $23.99 \pm 1.07^{\mathrm{b}}$ & $6.08 \pm 0.87^{\mathrm{a}}$ & $0.463 \pm 0.014^{\mathrm{a}}$ & $0.395 \pm 0.032^{\mathrm{a}}$ \\
Blue filter & $27.08 \pm 2.39^{\mathrm{a}}$ & $5.72 \pm 0.52^{\mathrm{a}}$ & $0.422 \pm 0.021^{\mathrm{b}}$ & $0.352 \pm 0.027^{\mathrm{b}}$ \\
\hline
\end{tabular}

Skin pigments content: The Ant content with neutral and blue filters was similar to that of control, but all other filters exhibited a significantly lower values, especially the red and yellow filter treatment (Table 4). Various light quality treatments elevated the $\mathrm{Chl}$ content compared with the control, and in a comparison among the different filters, the green and blue filters exhibited the highest contents. The lowest contents were observed for the yellow filter treatment. The variation in flavonoid and total phenolic content was consistent among different filters with the highest amounts found in the green filter treatment, followed by the neutral and blue filters. The flavonoid content of all different light quality treatments was significantly higher than that of control, but no substantial differences were observed in the total phenolic content between the control and the yellow/red filters. Thus, neutral and blue filters could maintain the red appearance of peach fruits, and various light qualities slowed down the degradation of skin Chl prior to fruit maturation in peaches, leading to improved oxidation resistance.

Fruit mass and firmness: The results showed that the effect of light quality on a fruit size was considerable (Table 5). The yellow filter treatment induced the largest fruit, which was $11.7 \%$ bigger than that of the control, and the green filter led to the smallest fruits, which was only $75.2 \%$ of the control. In addition, the red and blue filters also resulted in significantly smaller fruits compared with the control, while the size in the neutral filter treatment was consistent with the control. Moreover, different light quality treatments elevated fruit firmness. Other than yellow filter, all other filters improved fruit firmness with skin. In terms of firmness without skin, all filters also produced substantial increases compared with the control, especially under the red and blue filters.

Soluble sugar, sugar alcohol, selected organic acid contents, and SSC: The filter treatments had significant impacts on the fruit sugar content in peaches (Table 6). All of the sugar components under the neutral filter treatment exhibited the highest values and were significantly higher than those of the control. The glucose, fructose, and sorbitol contents of the green and blue filters were statistically the same as the control, but the red and yellow filters exhibited relatively low contents of the sugar 
Table 5. Effect of light quality on fruit mass and firmness in peach. Data represent means $\pm \mathrm{SD}$ of three replicates. For each variable, means with different lowercase letters are significantly different at $P<0.05$.

\begin{tabular}{llll}
\hline Treatment & Fruit mass $[\mathrm{g}]$ & Firmness with skin $[\mathrm{N}]$ & Firmness without skin $[\mathrm{N}]$ \\
\hline Control & $256.27 \pm 7.18^{\mathrm{b}}$ & $58.02 \pm 2.41^{\mathrm{b}}$ & $26.07 \pm 1.30^{\mathrm{d}}$ \\
Neutral filter & $252.80 \pm 5.66^{\mathrm{b}}$ & $74.48 \pm 1.34^{\mathrm{a}}$ & $29.89 \pm 0.72^{\mathrm{c}}$ \\
Red filter & $224.55 \pm 9.31^{\mathrm{c}}$ & $74.58 \pm 1.72^{\mathrm{a}}$ & $34.99 \pm 1.14^{\mathrm{a}}$ \\
Yellow filter & $286.32 \pm 9.86^{\mathrm{a}}$ & $62.43 \pm 3.53^{\mathrm{b}}$ & $28.71 \pm 0.81^{\mathrm{c}}$ \\
Green filter & $192.79 \pm 8.67^{\mathrm{d}}$ & $73.11 \pm 1.39^{\mathrm{a}}$ & $31.75 \pm 0.39^{\mathrm{b}}$ \\
Blue filter & $235.42 \pm 9.84^{\mathrm{c}}$ & $75.17 \pm 1.50^{\mathrm{a}}$ & $34.30 \pm 1.13^{\mathrm{a}}$ \\
\hline
\end{tabular}

Table 6. Effect of light quality on soluble sugar, sugar alcohol, and selected organic acid contents (all in $\left.\mathrm{g} \mathrm{kg}^{-1}\right)$ in peach. Data represent means \pm SD of three replicates. For each variable, means with different lowercase letters are significantly different at $P<0.05$.

\begin{tabular}{llllllll}
\hline Treatment & Sucrose & Glucose & Fructose & Sorbitol & Malic acid & Citric acid & Quinic acid \\
\hline Control & $57.48 \pm 1.67^{\mathrm{b}}$ & $15.71 \pm 1.92^{\mathrm{b}}$ & $14.05 \pm 1.05^{\mathrm{b}}$ & $10.56 \pm 2.66^{\mathrm{bc}}$ & $3.25 \pm 0.10^{\mathrm{a}}$ & $1.11 \pm 0.04^{\mathrm{c}}$ & $0.99 \pm 0.18^{\mathrm{a}}$ \\
Neutral filter & $76.96 \pm 1.59^{\mathrm{a}}$ & $21.56 \pm 2.44^{\mathrm{a}}$ & $18.38 \pm 1.02^{\mathrm{a}}$ & $15.33 \pm 2.56^{\mathrm{a}}$ & $3.06 \pm 0.09^{\mathrm{a}}$ & $1.04 \pm 0.09^{\mathrm{d}}$ & $1.07 \pm 0.11^{\mathrm{a}}$ \\
Red filter & $35.20 \pm 2.55^{\mathrm{d}}$ & $12.52 \pm 1.48^{\mathrm{c}}$ & $11.37 \pm 1.18^{\mathrm{c}}$ & $5.50 \pm 0.79^{\mathrm{d}}$ & $3.32 \pm 0.19^{\mathrm{a}}$ & $1.19 \pm 0.06^{\mathrm{b}}$ & $1.10 \pm 0.16^{\mathrm{a}}$ \\
Yellow filter & $41.68 \pm 2.99^{\mathrm{c}}$ & $11.96 \pm 1.04^{\mathrm{c}}$ & $10.30 \pm 1.51^{\mathrm{c}}$ & $8.96 \pm 2.12^{\mathrm{c}}$ & $3.06 \pm 0.18^{\mathrm{a}}$ & $0.86 \pm 0.07^{\mathrm{e}}$ & $0.98 \pm 0.15^{\mathrm{a}}$ \\
Green filter & $45.75 \pm 3.51^{\mathrm{c}}$ & $16.09 \pm 1.42^{\mathrm{b}}$ & $15.47 \pm 0.54^{\mathrm{b}}$ & $11.57 \pm 2.57^{\mathrm{b}}$ & $3.33 \pm 0.76^{\mathrm{a}}$ & $1.28 \pm 0.13^{\mathrm{a}}$ & $1.11 \pm 0.16^{\mathrm{a}}$ \\
Blue filter & $45.06 \pm 3.39^{\mathrm{c}}$ & $16.39 \pm 1.44^{\mathrm{b}}$ & $15.75 \pm 1.48^{\mathrm{b}}$ & $9.76 \pm 1.34^{\mathrm{bc}}$ & $3.05 \pm 0.23^{\mathrm{a}}$ & $1.03 \pm 0.05^{\mathrm{d}}$ & $1.19 \pm 0.18^{\mathrm{a}}$ \\
\hline
\end{tabular}

Table 7. Effect of light quality on soluble solid content (SSC), total sugar, and total acid contents in peach. Data represent means \pm SD of three replicates. For each variable, means with different lowercase letters are significantly different at $P<0.05$.

\begin{tabular}{lllll}
\hline Treatment & SSC $\left[{ }^{\circ}\right.$ Brix $]$ & Total sugar $\left[\mathrm{g} \mathrm{kg}^{-1}\right]$ & Total acid $\left[\mathrm{g} \mathrm{kg}^{-1}\right]$ & Sugar/acid ratio \\
\hline Control & $17.20 \pm 1.44^{\mathrm{a}}$ & $97.79 \pm 1.63^{\mathrm{b}}$ & $5.35 \pm 0.30^{\mathrm{a}}$ & $18.36 \pm 2.58^{\mathrm{b}}$ \\
Neutral filter & $16.59 \pm 1.03^{\mathrm{a}}$ & $132.23 \pm 1.73^{\mathrm{a}}$ & $5.17 \pm 0.28^{\mathrm{a}}$ & $25.64 \pm 2.41^{\mathrm{a}}$ \\
Red filter & $13.48 \pm 0.41^{\mathrm{c}} 64.59 \pm 6.66^{\mathrm{c}}$ & $5.62 \pm 0.48^{\mathrm{a}}$ & $11.57 \pm 1.62^{\mathrm{c}}$ \\
Yellow filter & $14.41 \pm 0.61^{\mathrm{b}} 72.90 \pm 5.44^{\mathrm{c}}$ & $4.90 \pm 0.53^{\mathrm{a}}$ & $15.10 \pm 2.75^{\mathrm{b}}$ \\
Green filter & $17.00 \pm 0.87^{\mathrm{a}}$ & $88.87 \pm 2.82^{\mathrm{b}}$ & $5.73 \pm 0.69^{\mathrm{a}}$ & $16.23 \pm 2.50^{\mathrm{b}}$ \\
Blue filter & $14.54 \pm 0.62^{\mathrm{b}} 86.97 \pm 1.87^{\mathrm{b}}$ & $5.27 \pm 0.60^{\mathrm{a}}$ & $16.67 \pm 1.90^{\mathrm{b}}$ \\
\hline
\end{tabular}

components. The sucrose content in the red filter treatment was the lowest, and it was significantly lower than the control in all treatments except the neutral filter. No significant differences in malic acid and quinic acid content were seen between various treatments. Contents of citric acid were higher in both green and red filter treatments than that of control, with the highest in the green filter treatment; while neutral, blue, and yellow filters showed a reduced content compared with the control, with the lowest one found in the yellow filter treatment.

The SSC under the green and neutral filter treatments was comparable to that of the control, and it displayed significantly lower contents for the other filters, especially

\section{Discussion}

Light quality vs. photosynthetic and Chl fluorescence characteristics: $\mathrm{Chl}$ is the main pigment of photosynthesis in plants. Our data indicated that the green filter treatment resulted in the lowest $\mathrm{Chl}$ content, which was consistent with the results of Heraut-Bron et al. (1999). In addition, the $P_{\mathrm{N}}$ and $E$ were significantly reduced in the blue and the red filter treatment (Table 7). The highest total sugar content was observed with the neutral filter, then the green and blue filters, which were similar to the control, and the lowest content was seen in the red and yellow treatments. The amount of total acid was comparable between the different treatments. The sugar acid ratio was increased by the neutral filter but reduced by the red filter compared with the control. The other filters exhibited similar contents as the control.

The above data indicated that the neutral filter treatment facilitated the accumulation of soluble carbohydrates in peach fruits, resulting in an improvement in fruit edible qualities.

green filter treatments, and WUE, LUE, and CUE also dropped to their lowest level, which occurred probably due to the low amount of red light allowed to pass in these two filters (Table 1). The low R/FR ratio further inhibited the synthesis of $\mathrm{Chl}$, and affected the water, light, and $\mathrm{CO}_{2}$ utilization. However, the present study also demonstrated 
that, although the photosynthetic indicators of leaves in the blue filter treatment were lower than those of control, the Chl content increased, which is consistent with Buschmann et al. (1978). Moreover, due to much more red light and higher R/FR ratio under the neutral filter than other types of filters, the elevation in $P_{\mathrm{N}}$, WUE, LUE, and CUE under this treatment promoted the transportation of photosynthetic products to fruits, leading to the improvement of the total sugar accumulation in the fruits (Table 2, Table 8). Light quality affects photosynthesis both through effects on the composition of the photosynthetic apparatus and on translocation of carbohydrates from chloroplasts (Sæbø et al. 1995). In the present study, $P_{\mathrm{N}}$ and $\mathrm{L}_{\mathrm{s}}$ were significantly reduced and $C_{\mathrm{i}}$ increased in the yellow, green, and blue filter treatments compared with the control (Table 2), suggesting that the decrease of $P_{\mathrm{N}}$ under these three filter types was not caused by the change in $g_{\mathrm{s}}$, but by the lesser transmittance of red light under these filters which caused the reduction of photosynthetic activity in mesophyll cells.

Chl fluorescence parameters are used to describe the photosynthesis mechanisms and photosynthetic physiological status of plant leaves, and to reflect the intrinsic characteristics of plants, which serve as an internal probe for studying the relationship between photosynthesis and the environment (Genty et al. 1989). Light quality of different light sources affected leaf PSII photochemical efficiency and electron transport efficiency (Ramalho et al. 2002). In the present study, it was observed that $F_{v} / F_{m}$ and ETR of neutral, red, and yellow filter treatments, which had higher $\mathrm{R} / \mathrm{B}$ than the other types of filters, was significantly higher than control, indicating that PSII photochemical efficiency and electron transport capacity in peach leaves were promoted by light quality. In addition, both activity and primary electron transport efficiency of PSII were positively enhanced by R/B. We observed that peach trees grown under neutral, red, and yellow filters showed reduced $\Phi_{\mathrm{PSII}}$ and $\mathrm{q}_{\mathrm{P}}$ compared to the blue filter treatment because more blue light under blue filter was more crucial for the efficient function of PSII than red light. The results suggest that the reduction in $\Phi_{\text {PSII }}$ under a certain kind of light is mostly attributed to the reduction of $\mathrm{q}_{\mathrm{P}}$ since $\Phi_{\mathrm{PSII}}$ is the product of $\mathrm{q}_{\mathrm{P}}$ and the efficiency of excitation energy captured by the open PSII reaction centers ( $\mathrm{Yu}$ and Ong 2003, Wang et al. 2009). However, $P_{\mathrm{N}}$ under the green and blue filters was greatly reduced in comparison with that of control, although $\Phi_{\mathrm{PSII}}$, $\mathrm{q}_{\mathrm{p}}$, and ETR were elevated and $\mathrm{F}_{\mathrm{v}} / \mathrm{F}_{\mathrm{m}}$ did not vary. Although there was not enough red light under green and blue filter, the good ETR could supply sufficient ATP and NADPH for the Calvin-Benson cycle of peach leaves. In addition, $\mathrm{q}_{\mathrm{N}}$ and NPQ stayed at a relatively high level under neutral and red filters, resulting in a reduction of

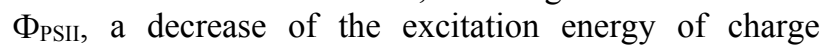
separation in the reaction center, and an increase in the dissipation of the xanthophyll cycle.
The skin pigment content and color difference index $v s$. light quality: Many studies have reported that Ant biosynthesis is an important process that depends on light quality (Dussi et al. 1995, Ubi et al. 2006). The shortwave radiation and altered FR/R around fruits, which are treated by different colored filters, can be improved. As a result, apple, pear, and strawberry skins were influenced by light quality (Dussi et al. 1995, Feng et al. 2013, Miao et al. 2016). We demonstrated that different light quality filters have varying impacts on fruit color. The correlation coefficient of skin $a^{*}, a^{*} / b^{*}$ and Ant content to $h^{\circ}$ was $0.9936,-0.9983$, and -0.9111 , respectively, indicating that the higher the skin pigment content is, the higher $a^{*}$ value is, the redder the fruit is and the smaller the $h^{\circ}$ is (Francis 1980). No significant difference in $a^{*}, a^{*} / b^{*}$, and Ant content was observed in neutral and blue filter treatments compared with the control, and the Chl content under the blue filter was higher than that of the control and neutral filter. During the ripening stage, more and more red appearance with less and less green appearance of peach skin turned on (Zhang et al. 2015), indicating that the accumulation of Ant and reduction of Chl related to the ripening process. Different filters with various light quality affected skin colors of peach at the maturity stage. Fruits under blue filter having the higher $\mathrm{Chl}$ content might be due to the lower R/FR. In addition, light quality may regulate the pigment synthesis of peach fruit by altering the gene expression (Liu et al. 2004, Feng et al. 2013), and more investigation is needed to illustrate its mechanism.

Internal quality of peach fruit vs. light quality: The internal quality of fruit is a comprehensive quality reflected by the inner soluble sugar and titratable acid composition (Widmer 2001, Ni et al. 2011).

Sucrose is the major sugar component in the mature peach fruit (Vizzoto et al. 1996), followed by glucose, fructose, and sorbital, while malic acid, citric acid, and quinic acid are the main components of organic acids (Wang et al. 1993, Svanella et al. 1999). Here, we demonstrated that sucrose is still the dominant sugar component in the peach variety 'Xiahui 8 ' under various light quality treatments. So light quality did not affect the accumulation form of sugars and organic acid components in the peach fruit. Comparing all the treatments, the neutral filter treatment exhibited the highest content of sucrose, glucose, fructose, sorbitol, total sugar content, and sugar acid ratio, and its SSC was similar to that of the control, suggesting neutral filter improved fruit quality. The red filter showed the lowest sugar acid ratio among all treatments, and its SSC and sugar contents were also low, exhibiting a poor comprehensive quality. Further investigations are needed to understand the mechanisms underlying the effects of light quality on the sugar metabolism in peach fruits. The organic acid content of fruits was not significantly affected by different light quality filters, which indicated that the organic acid 
accumulation in peach fruits is largely influenced by genetic factors rather than environmental conditions such as light quality.

Overall, the yellow filter maintained relatively high $P_{\mathrm{N}}$ and $\mathrm{Chl}$ content in peach leaves, and it also increased single fruit mass, but its effect on fruit coloring was poor, leading to a decrease in internal quality. Leaves of green and blue filter treatments exhibited weak light energy and $\mathrm{CO}_{2}$ utilization. Although the green filter facilitated the inner quality of fruits, the fruit coloring was not good, and the fruit size was small. The blue filter can maintain a good appearance in terms of fruit coloring, but fruits grown

\section{References}

Adams-Phillips L., Barry C., Giovannoni J.: Signal transduction systems regulating fruit ripening. - Trends Plant Sci. 9: 331338, 2004.

Bastías R.M., Corelli-Grappadelli L.: Light quality management in fruit orchards: physiological and technological aspects. Chil. J. Agr. Res. 72: 574-581, 2012.

Batschauer A.: Photoreceptors of higher plants. - Planta 206: 479-492, 1998.

Brecht J.K., Huber D.J., Sherman M. et al.: Methyl bromide inhibits ripening and ethylene production in tomato (Lycopersicon esculentum Mill.) fruit. - Plant Growth Regul. 5: 29-35, 1986.

Buschmann C., Meier D., Kleudgen H.K. et al.: Regulation of chloroplast development by red and blue light. - Photochem. Photobiol. 27: 195-198, 1978.

Cleland R.E., Melis A., Neale P.J.: Mechanism of photoinhibition: photochemical reaction center inactivation in photo systém II of chloroplasts. - Photosynth. Res. 9: 79-88, 1986.

Dussi M.C., Sugar D., Wrolstad R.E.: Characterizing and quantifying anthocyanins in red pears and the effect of light quality on fruit color. - J. Am. Soc. Hortic. Sci. 120: 785-789, 1995.

Feng F., Li M., Ma F. et al.: Phenylpropanoid metabolites and expression of key genes involved in anthocyanin biosynthesis in the shaded peel of apple fruit in response to sun exposure. Plant Physiol. Bioch. 69: 54-61, 2013.

Francis F.J.: Color quality evaluation of horticultural crops. HortScience 15: 58-59, 1980.

Fukumoto L.R., Mazza G.: Assessing antioxidant and prooxidant activities of phenolic compounds. - J. Agr. Food Chem. 48: 3597-3604, 2000

Genty B., Briantais J.M., Baker N.R.: The relationship between the quantum yield of photosynthetic electron transport and quenching of chlorophyll fluorescence. - Biochim. Biophys. Acta 990: 87-92, 1989

Guan H.P., Janes H.W.: Light regulation of sink metabolism in tomato fruit. - Plant Physiol. 96: 916-921, 1991.

Heraut-Bron V., Robin C., Varlet-Grancher C. et al.: Light quality (red: far-red ratio): does it affect photosynthetic activity, net $\mathrm{CO}_{2}$ assimilation, and morphology of young white clover leaves? - Can. J. Bot. 77: 1425-1431, 1999.

Hudina M., Stampar F.: Bagging of 'Concorde' pears (Pyrus communis L.) influences fruit quality. - Acta Hortic. 909: 625630, 2011

Iglesias I., Alegre S.: The effect of anti-hail nets on fruit protection, radiation, temperature, quality and profitability of under the blue filter showed a significant decline in internal quality. Leaves under red filter treatments showed a relatively high photosynthetic capability, but the fruit quality in terms of SSC and sugar content were greatly reduced, leading to an undesirable taste. The leaf photosynthetic ability and internal quality under the neutral filter treatment were elevated compared with the control, and the appearance color was the same as the control. Therefore, the application of neutral filter in the rain-shelter cultivation of 'Xiahui 8 ' peach is recommended, because it can maintain a relatively high photosynthetic capability and improve the fruit quality.

'Mondial Gala' apples. - J. Appl. Hortic. 8: 91-100, 2006.

Infante R., Contador L., Rubio P. et al.: Postharvest sensory and phenolic characterization of 'Elegant Lady' and 'Carson' peaches. - Chil. J. Agr. Res. 71: 445-451, 2011.

Kircher S., Kozma-Bognar L., Kim L. et al.: Light qualitydependent nuclear import of the plant photoreceptors phytochrome A and B. - Plant Cell 11: 1445-1456, 1999.

Koukounaras A., Siomos A.S., Sfakiotakis E.: Impact of heat treatment on ethylene production and yellowing of modified atmosphere packaged rocket leaves. - Postharvest Biol. Tec. 54: 172-176, 2009.

Koyama K., Ikeda H., Poudel P.R. et al.: Light quality affects flavonoid biosynthesis in young berries of Cabernet Sauvignon grape. - Phytochemistry 78: 54-64, 2012.

Lichtenthaler H.K., Wellburn A.R.: Determinations of total carotenoids and chlorophylls $a$ and $b$ of leaf extracts in different solvents. - Biochem. Soc. T. 11: 591-592, 1983.

Liu Y.S., Roof S., Ye Z.B. et al.: Manipulation of light signal transduction as a means of modifying fruit nutritional quality in tomato. - P. Natl. Acad. Sci. USA 101: 9897-9902, 2004.

Ma R.J., Zhang B.B., Yan J. et al.: [Effects of light wave on coloration and quality in 'Flavortop' nectarine fruit.] Nonwood Forest Res. 32: 109-113, 2014. [In Chinese]

Ma R.J., Zhang B.B., Cai Z.X.: [Evaluation of peach rootstock waterlogging tolerance based on the responses of the photosynthetic indexes to continuous submergence stress.] Acta Hortic. Sin. 40: 409-416, 2013. [In Chinese]

Marshall B., Biscoe P.V.: A model for C3 leaves describing the dependence of net photosynthesis on irradiance. - J. Exp. Bot. 31: 29-39, 1980.

Maxwell K., Johnson G.N.: Chlorophyll fluorescence: a practical guide. - J. Exp. Bot. 51: 659-668, 2000.

Miao L.X., Zhang Y.C., Yang X.F. et al.: Colored light-quality selective plastic films affect anthocyanin content, enzyme activities, and the expression of flavonoid genes in strawberry (Fragaria $\times$ ananassa) fruit. - Food Chem. 207: 93-100, 2016.

Mitchell F.G., Mayer G., Maxie E.C. et al.: Cold storage effects on fresh market peaches, nectarines \& plums: estimating freezing points; using low temperatures to delay internal breakdown. - Calif. Agr. 28: 12-14, 1974.

Ni Z.J., Zhang Z., Gao Z.H. et al: Effects of bagging on sugar metabolism and the activity of sugar metabolism related enzymes during fruit development of Qingzhong loquat. - Afr. J. Biotechnol. 10: 4212-4216, 2011.

Nijs I., Ferris R., Blum H. et al.: Stomatal regulation in a changing climate: a field study using free air temperature 
increase (FATI) and free air $\mathrm{CO}_{2}$ enrichment (FACE). - Plant Cell Environ. 20: 1041-1050, 1997.

Poudel P.R., Kataoka I., Mochioka R.: Effect of red- and bluelight-emitting diodes on growth and morphogenesis of grapes. - Plant Cell Tiss. Org. 92: 147-153, 2008.

Pourmorad F., Hosseinimehr S.J., Shahabimajd N.: Antioxidant activity, phenol and flavonoid contents of some selected Iranian medicinal plants. - Afr. J. Biotechnol. 5: 1142-1145, 2006.

Ramalho J.C., Marques N.C., Semedo J.N. et al.: Photosynthetic performance and pigment composition of leaves from two tropical species is determined by light quality. - Plant Biol. 4: 112-120, 2002.

Rapparini F., Rotondi A., Baraldi R.: Blue light regulation of the growth of Prunus persica plants in a long term experiment: morphological and histological observations. - Trees 14: 169176, 1999.

Sæbø A., Krekling T., Appelgren M.: Light quality affects photosynthesis and leaf anatomy of birch plantlets in vitro. Plant Cell Tiss. Org. 41: 177-185, 1995.

Schuerger A.C., Brown C.S., Stryjewski E.C.: Anatomical features of pepper plants (Capsicum annuum L.) grown under red light-emitting diodes supplemented with blue or far-red light. - Ann. Bot.-London 79: 273-282, 1997.

Shibuya T., Endo R., Hayashi N. et al.: High-light-like photosynthetic responses of Cucumis sativus leaves acclimated to fluorescent illumination with a high red: far-red ratio: interaction between light quality and quantity. Photosynthetica 50: 623-629, 2012.

Svanella L., Gaudillère M., Gaudillère J.P. et al.: Organic acid concentration is little controlled by phosphoenolpyruvate carboxylase activity in peach fruit. - Funct. Plant Biol. 26: 579$585,1999$.

Tawaha K., Alali F.Q., Gharaibeh M. et al.: Antioxidant activity and total phenolic content of selected Jordanian plant species. - Food Chem. 104: 1372-1378, 2007.

Ubi B.E., Honda C., Bessho H. et al.: Expression analysis of anthocyanin biosynthetic genes in apple skin: effect of UV-B and temperature. - Plant Sci. 170: 571-578, 2006.

van Kooten O., Snel J.F.H.: The use of chlorophyll fluorescence nomenclature in plant stress physiology. - Photosyn. Res. 25: 147-150, 1990.

Vizzotto G., Pinton R., Varanini Z. et al.: Sucrose accumulation in developing peach fruit. - Physiol. Plantarum 96: 225-230, 1996.

Voss D.H.: Relating colorimeter measurement of plant color to the Royal Horticultural Society colour chart. - HortScience 27: 1256-1260, 1992.

Wang H., Gu M., Cui J.X. et al.: Effects of light quality on $\mathrm{CO}_{2}$ assimilation, chlorophyll-fluorescence quenching, expression of Calvin cycle genes and carbohydrate accumulation in Cucumis sativus. - J. Photoch. Photobio. B 96: 30-37, 2009.

Wang T., Gonzalez A.R., Gbur E.E. et al.: Organic acid changes during ripening of processing peaches. - J. Food Sci. 58: 631632, 1993.

Widmer A.: Light intensity and fruit quality under hail protection nets. - Acta Hortic. 557: 421-426, 2001.

Xiong J.Q., Patil G.G., Moe R. et al.: Effects of diurnal temperature alternations and light quality on growth, morphogenesis and carbohydrate content of Cucumis sativus L. - Sci. Hortic.Amsterdam 128: 54-60, 2011.

Yu H., Ong B.L.: Effect of radiation quality on growth and photosynthesis of Acacia mangium seedlings. Photosynthetica 41: 349-355, 2003.

Zapsalis C., Francis F.J.: Cranberrv anthocyanins. - J. Food Sci. 30: 396-399, 1965.

Zhang B.B., Jiang W.B., Weng M.L. et al.: [Effects of shading on photosynthetic characteristics of red-leaf peach.] - Acta Hortic. Sin. 37: 1287-1294, 2010. [In Chinese]

Zhang B.B., Guo J.Y., Ma R.J. et al.: Relationship between the bagging microenvironment and fruit quality in 'Guibao' peach [Prunus persica (L.) Batsch]. -J. Hortic. Sci. Biotech. 90: 303310, 2015. 